\title{
Pandemics and Economic Growth: Evidence from the 1968 H3N2 Influenza
}

\author{
Yothin Jinjarak ${ }^{1} \cdot$ Ilan Noy $^{1} \cdot$ Quy Ta ${ }^{1}$ (D)
}

Received: 27 May 2021 / Accepted: 25 August 2021 / Published online: 12 October 2021

(c) The Author(s), under exclusive licence to Springer Nature Switzerland AG 2021

\begin{abstract}
We evaluate the 1968 H3N2 Flu pandemic's economic cost in a cross-section of 52 countries. Using excess mortality rates as a proxy for the country-specific severity of the pandemic, we find that the average mortality rate $(0.0062 \%$ per pandemic wave $)$ was associated with a decline in output of $2.4 \%$ over the two pandemic waves. Our estimates also suggest the losses in consumption $(-1.9 \%)$, investment $(-1.2 \%)$, and productivity $(-1.9 \%)$ over the two pandemic waves. The results are robust across regressions using alternative measures of mortality and output loss. The study adds to the current literature new empirical evidence on the economic consequences of the past pandemics in light of the potential impacts of the Covid-19 pandemic on productivity.
\end{abstract}

Keywords Output loss $\cdot$ Productivity $\cdot$ Pandemics $\cdot$ Hong Kong flu $\cdot$ H3N2

JEL Classifications E65 $\cdot$ I15 $\cdot$ Q54

\section{Introduction}

The spread of a new coronavirus (Covid-19) in early 2020 has caught the world by surprise and led to a dramatic contraction in the global economy. Our understanding of pandemics' macroeconomic impact was limited, based only a handful of studies on previous pandemic outbreaks. There were three significant global influenza pandemics since the early twentieth century: 1918,1957 , and $1968 .{ }^{1}$ The first one, in 1918-1920, was by far the most catastrophic and has received the most research attention (e.g., Beach et al. 2020).

1 The more recent 2009 'Swine flu' H1N1 pandemic turned out to be significantly less costly that feared at its onset. There is also research evaluating the economic impacts of the 2009 Swine Flu (e.g. Rassy and Smith 2013). Another recent coronavirus pandemic, SARS, has been researched more, but its spatial spread was limited to a few countries (Noy and Shields 2019).

This article is part of the Topical Collection on Economics of COVID-19

Quy Ta

quy.ta@vuw.ac.nz

1 School of Economics and Finance, Victoria University of Wellington, RH 328, Rutherford House, 23 Lambton Quay, PO Box 600, Wellington 6140, New Zealand 
Why are there so few empirical studies evaluating the impact of past pandemics on economic growth more generally? Apart from the fact that those events are thankfully rare, data constraint is an important factor explaining this gap in our current knowledge, especially for events before the twenty-first century. Only a few empirical studies estimate the adverse impacts of the 1918 Influenza at the aggregate level (e.g., Karlsson et al. 2014; Barro et al. 2020; Bodenhorn 2020; Dahl et al. 2020). Yet, even for the 1918 pandemic, the difficulties in separating the pandemic's impact from the war and the paucity of reliable data have prevented much quantification of its economic impact (Noy et al. 2020). Here, in contrast, we focus on the 1968 influenza pandemic, an event that is closer in time, documented with a lot more economic data and probably more reliable mortality data, and can better serve as a useful comparator to the current global predicament. Surprisingly, though, the 1968 pandemic's consequence on economic growth has yet to be studied. This is what we undertake herein.

For the current Covid-19 pandemic, recent works attempt to identify the pandemic's adverse effects on economic growth separately through demand and supply channels. Demand-side channels capture the consequential effects on consumption, investment, trade, and travel, while supply channels reflect workforce and supply-chain disruptions and the rising costs of doing business (Guerrieri et al. 2020; World Bank 2020).

Besides the useful distinction between demand and supply effects, another important puzzle is whether epidemics can affect longer-term productivity and growth. In principle, pandemics could affect labor productivity through their direct impact on human health and indirectly by affecting skill acquisition and capital investment. In principle, an influenza epidemic can have permanent consequences on the productivity of an economy. Even if the productivity growth rate returns to its pre-pandemic value, it might be that the productivity level will always lie below the path it would have followed in the absence of the epidemic. The objective of our study is to assess how large these effects are empirical. To the best of our knowledge, only Guimbeau et al. (2020) studied and found negative effects of the 1918 influenza on agricultural productivity using districtlevel data in the Brazilian city of Sao Paulo.

Here, we investigate the impact of the 1968 H3N2 influenza pandemic on output and productivity in a cross-section of 52 countries. The $\mathrm{H} 3 \mathrm{~N} 2$ was the first pandemic spreading rapidly through international air travel (Viboud et al. 2005). According to recent estimates, it affected 30-57 percent of the global population, with the mortality rates estimated in the range of $0.02-0.03$ percent. It was a less lethal pandemic than the H1N1 influenza pandemic of 1918 (World Bank 2020).

We contribute to the 'economics of pandemics' literature by analysing the economic cost of the H3N2 pandemic using historical data on mortality rates (two waves) obtained from the World Health Organization database on the International Classification of Diseases. We find that the pandemic reduced output growth rate by $2.4 \%$ cumulatively over the two seasons (mortality rate was $0.0062 \%$ per season) and productivity by $1.9 \%$. The evidence also shows that the pandemic shock led to a reduction in private consumption and investment by $1.9 \%$ and $1.2 \%$, respectively. Our study cannot incorporate the efficacy of non-pharmaceutical interventions due to the lack of data.

The rest of the paper is organized as follows. Pandemics and Development presents the background of the pandemic, and Data Description shows the data available. Empirical Specification describes the empirical specification, followed by the estimation results in Estimation Results. Conclusion concludes. 
Table 1 Estimated mortality and infection rates of the Influenza pandemics since the past century

\begin{tabular}{lllll}
\hline Event & $1918-1920$ & $1957-1958$ & $1968-1970$ & 2009-2010 \\
\hline Deaths (\% of global population) & $1.0-5.7$ & $0.03-0.05$ & $0.02-0.03$ & $0.001-0.004$ \\
Infections (\% of global population) & 28 & $42-55$ & $30-57$ & 24 \\
Reproduction number & 1.80 & 1.65 & 1.80 & 1.46 \\
\hline
\end{tabular}

Source: World Bank (2020); Biggerstaff et al. (2014).

\section{Pandemics and Development}

\section{Background of the H3N2 Flu Pandemic}

Three worldwide (pandemic) influenza outbreaks occurred in the last century, including the H1N1 pandemic in 1918-1920, the H2N2 pandemic in 1957-1958, and the H3N2 pandemic in 1968-1969; the three are also colloquially known as the Spanish, Asian, and Hong Kong flu pandemics. ${ }^{2}$ Each event differed from the others concerning the aetiological agent, its epidemiological characteristics, and the associated disease severity. These influenza pandemics did not occur at regular intervals. In the two that occurred with modern virology tools available (1957 and 1968), the causative viruses' antigen showed major changes from the corresponding antigens of immediately antecedent strains. Among the past events, the 1918 pandemic was the most severe, with the mortality rate ranging from 1 to 5 percent of the global population. However, the 1957 Influenza spread most widely, with more than $40 \%$ of the global population likely got infected (Table 1).

The influenza A (H3N2) virus combines two genes from an avian influenza A virus: the new H3 hemagglutinin and the N2 neuraminidase (from the 1957 H2N2 virus). Although the new disease-causing virus identified in 1968 was extremely transmissible (its reproduction number ${ }^{3}$ was similar to the H1N1 strain from 1918), the disease severity was milder than both previous flu pandemics. It emerged in Hong Kong on the $13^{\text {th }}$ of July 1968, and reached its maximum intensity in two weeks, lasting some six weeks in all with 500,000 cases in Hong Kong in July. The outbreak was the largest in Hong Kong since the 1957 pandemic (Jester et al., 2020). About 15\% of the population across all age groups was affected, but the mortality rate was low, and the clinical symptoms were typically mild (Chang 1969).

That year, the World Health Organization warned of its possible worldwide spread on 16 August 1968 and identified it as the cause for epidemic outbreaks in other parts of the world. Viboud et al. (2020) show that the H3N2 epidemic started in the last quarter of 1968 in the northern hemisphere countries, while the southern-hemisphere countries started to experience the epidemic in 1969. Air travel (an estimated 160 million persons during the pandemic) facilitated rapid transmission worldwide (Jester et al., 2020). Jackson et al. (2010) use various published data to estimate that the first-wave reproduction number

\footnotetext{
2 Since the current accepted standard, adopted by the WHO, is not to name a pandemic after the first publicized location of its emergence, we continue to refer to these events by the official influenza virus strain name.

3 Reproduction or basic reproduction number is defined as the average number of secondary cases associated with a typical infectious case. It is an important parameter of transmissibility.
} 
was between 1.1 and 2.1 , and the second-wave reproduction number was possibly higher, between 1.2 and 3.6.

The 1968 H3N2 flu caused between 500,000 and two million deaths in two waves (1968-1969 and 1969-1970). As the epidemic progressed (initially in Asia; Singapore, Taiwan, the Philippines, Vietnam, and Malaysia), geographic patterns of mortality emerged. In North America, most deaths occurred during the first pandemic season. In Europe and Asia, $70 \%$ of the deaths happened during the second pandemic season. ${ }^{4}$

\section{Economic Growth before the 1968 H3N2 Pandemic}

The 1960s saw a rapid expansion in real economic activity associating with high employment and investment, price stability, productivity improvement, and freer trade (FED 1967; United Nations 1969). For OECD countries, the rapid growth was due to a high capital formation rate ranging from $14 \%$ in the United Kingdom to $30 \%$ in Japan, coupled with significant human-capital accumulation. For the first half of the 1960s, a shift of labor out of agriculture increased productivity by $10 \%-15 \%$ in France, Germany, Italy, and Japan (FED 1967). Many developing countries were also recording high growth, thanks to capital inflows and their demographic dividends.

\section{Pandemics and Economic Growth}

A now growing body of literature has examined the economic costs of pandemics over the short-to-medium-term horizon. Pandemics' macroeconomic impacts could stem from effects on aggregate demand and aggregate supply adjustments. The expected loss in disposable income associated with the epidemic would reduce private consumption for the demand side. Lockdown and travel ban measures to slow the spread of the disease, for instance, can affect aggregate demand as well. Fear and uncertainty, and the disruptions associated with them, cause more precautionary behavior and a further drop in demand.

Social-distancing requirements reduce productivity and investment. The decline in international trade and the rising cost of doing business disrupt the global value chains, further compounding the supply side issues from workers' exposure to lockdown, infection, and mortality. Thus, the pandemics' supply-side effects are likely through lower productivity, adverse impact on investment, labor supply, and total factor productivity (Dieppe 2020; World Bank 2020). ${ }^{5}$

For the 1918 pandemic, Barro et al. (2020) find that it lowered real GDP and consumption by $6 \%$ and $8 \%$, respectively, in cross-country data. Dahl et al. (2020) find that

\footnotetext{
4 Viboud et al. (2020)'s findings suggest that the 1-year delay in mortality might be the most common experience in continents other than North America. They hypothesize that this phenomenon may be explained by the higher pre-existing neuraminidase immunity (from the A/H2N2 era) in other places rather than North America, combined with a subsequent drift in the neuraminidase antigen during 1969/1970.

5 Pandemics can also lead to permanent changes in productivity through other channels. For example, higher unemployment, especially among young workers, can lead to de-skilling or permanent loss of opportunities to acquire new skills, which can lead to persistent reductions in the accumulation of human capital. Besides, pandemics affect mental health in ways that may imperil labor productivity. While there are multiple channels through which productivity could be adversely affected, there might be other indirect effects on productivity. For example, a shift to work-from-home could, in principle, be productivity-improving for some sectors and occupations.
} 
it resulted in a V-shaped recession using municipality-level data from Denmark. Using regional data from Sweden, Karlsson et al. (2014) find that the 1918 pandemic led to a persistent increase in poverty rates and reduced capital return. Bodenhorn (2020), focusing on the Southern United States, find that the 1918 Influenza reduced retail sales and manufacturing activity. Garrett (2009) finds that geographic areas with higher influenza mortality saw a relative increase in wages from 1914 to 1919 census years, consistent with the effect of labor shortages. Guimbeau et al. (2020) find robust evidence of contemporary and persistent effects on health, educational attainment, and agricultural productivity using district-level data in the Brazilian city of Sao Paulo. Noy et al. (2020) examined the Japanese textile industry, and find that a prefecture with the mean excess mortality experienced a 28.3 percent reduction in annual textile output. There is so far no study on the H2N2 and H3N2 pandemics that can offer comparable lessons. ${ }^{6}$

The recent literature with regards to the ongoing Covid-19 pandemic has provided some useful insights. Martin et al. (2020) introduce a household-level model to assess the socioeconomic impacts of Covid-19 on per capita consumption losses and depletion of savings. Using an agent-based model of out-of-equilibrium economic dynamics to estimate the cost of the Covid-19 lockdowns, accounting both for direct impacts of the lockdowns and its propagation through the global supply chain, Mandel and Veetil (2020) estimate the total impact amounting to $9 \%$ of global GDP. Considering the demand perspective, Nakamura and Managi (2020) calculate the overall relative risk of the importation and exportation of Covid-19 from every airport in local municipalities around the world, based on global spatial and mapping information under three scenarios of air travel restriction. The relative risk of importation and exportation of Covid-19 clearly shows that not only China, Europe, Middle East, and East Asia, but also the U.S., Australia, and countries in Northeast Asia and Latin America are subject to such risk.

Likewise, in a two-step Vector Auto-Regressive (VAR) model to forecast the effect of the virus outbreak on the economic output of the New York state, Gharehgozli et al. (2020) predict annualized quarterly growth rate of real GDP to be between $-4 \%$ to $-4.3 \%$ for the first quarter and between $-19.8 \%$ to $-21.7 \%$ for the second quarter of 2020 . Considering an artificial neural network model to forecast GDP loss in eight major countries, the findings show that the April to June quarters of 2020 saw a significant decline in economic growth in all countries while the annualized GDP growth is expected to reach double-digit negative growth rates in most countries (Jena et al. 2021).

NPIs might play a role in mitigating the economic decline from a pandemic by reducing the spread of the virus and thus retaining more confidence in business activity and investment. For instance, Kurita and Managi (2020) and Katafuchi et al. (2020) point out that social stigma can effectively prevent people from going out and possibly spreading Covid19 infection. These studies show both theoretical analysis and empirical evidence that nonlegally binding Covid-19 policies, i.e., a declared state of emergency reduce the share of people going out through self-restraint behaviour.

\footnotetext{
6 There is some research estimating the economic consequences of other biological disasters since the 1980s (including AIDS, SARS, Ebola, and Zika, e.g., Lee and McKibbin 2004; Siu and Wong 2004; Keogh-Brown and Smith 2008; Joo et al. 2019; and Noy and Shields 2019), and some evaluating the impacts of the current Covid-19 pandemic (e.g., Andersen et al. 2020; Baker et al. 2020; Banco de Espana 2020; Chen et al. 2020; Coibion et al. 2020; and Guerrieri et al. 2020). The former is not directly relevant, given the differences in the epidemioloigical characteristics of the diseases involved.
} 
Table 2 Excess mortality and economic outcomes during the H3N2 pandemic

\begin{tabular}{llllllc}
\hline & & Obs & Mean & S.D & Min & Max \\
\hline excess_a (baseline, in \%) & All & 52 & 0.0076 & 0.0062 & 0 & 0.0233 \\
& Northern hemisphere & 43 & 0.0068 & 0.0068 & 0 & 0.0233 \\
& Southern hemisphere & 9 & 0.0115 & 0.0115 & 0.003 & 0.0217 \\
excess_b & All & 52 & 0.0085 & 0.0069 & 0 & 0.025 \\
(in \%) & Northern hemisphere & 43 & 0.0079 & 0.0071 & 0 & 0.025 \\
& Southern hemisphere & 9 & 0.0115 & 0.0115 & 0.003 & 0.0217 \\
excess_c & All & 52 & 0.0066 & 0.0059 & 0 & 0.0224 \\
(in \%) & Northern hemisphere & 43 & 0.0061 & 0.0058 & 0 & 0.0224 \\
& Southern hemisphere & 9 & 0.0090 & 0.0060 & 0 & 0.0189 \\
Output & Output1 (baseline) & 52 & 1.30 & 2.74 & -8.35 & 6.61 \\
& Output2 & 52 & 1.54 & 3.79 & -12.32 & 10.48 \\
& Output3 & 52 & 1.12 & 2.74 & -8.71 & 6.89 \\
Productivity & Labor productivity & 46 & 1.61 & 2.92 & -9.35 & 7.24 \\
(baseline) & TFP & 45 & 2.74 & 2.81 & -7.14 & 8.58 \\
Consumption (baseline) & & 52 & 1.43 & 4.29 & -8.39 & 13.13 \\
Investment (baseline) & & 52 & 0.91 & 1.79 & -2.83 & 6.54 \\
\hline
\end{tabular}

Source: WHO, PWT 9.1, and authors' calculation.

Baseline: Averaged 1968-70 deviation (for the Northern hemisphere) and averaged 1969-70 deviation (for the Southern hemisphere) from pre-pandemic (1965-67).

Output 2; excess_b: Averaged 1969-70 deviations from pre-pandemic (1965-67).

Output3; excess_c: Averaged 1968-70 deviation (for the Northern hemisphere) and averaged 1969-70 deviation (for the Southern hemisphere) from pre-pandemic (1963-67).

\section{Data Description}

\section{Defining Excess Mortality}

Most influenza victims die of pneumonia or pneumonia-like complications that develop due to the immune system's response to the viral infection (Viboud et al., 2016; Bodenhorn 2020). Regarding the severity of a pandemic across countries, excess mortality rate - the number of deaths in the pandemic years over the population relative to the average pre-pandemic mortality rate, is considered a better measure than measured infection rate. The heterogeneous mortality patterns from a pandemic indeed reflect differences in how effectively countries have managed the associated outbreaks, the resilience of the economy, and the preparedness of their healthcare system. Thus, the baseline index for pandemic intensity ( "excess_a" variable in Table 2) is the average annual excess mortality rate (i.e., excess deaths as a percent of the population) caused by Influenza and pneumonia during the two pandemic seasons of $1968 / 69$ and 1969/70. Data on mortality rates are from the International Classification of Diseases of WHO (versions ICD-7 and ICD-8): the main disease codes $470-517$ and 480-493. A caveat is the mortality data is available only on annual basis from WHO. Subject to the data availability, we have 52 countries in the sample including mostly high-income countries and some upper-middle-income countries. 
Excess deaths are the number of deaths in the pandemic years relative to the average pre-pandemic mortality rate for 1965-1967. Also, as mortality data is available from the past pandemics in the twentieth century, related works in the literature use excess mortality rates to examine their impacts on the economic dependent variables (e.g., Viboud et al., 2016; Correia et al. 2020; Barro et al. 2020; Bodenhorn 2020; Dahl et al. 2020, and Noy et al. 2020). In particular, our excess mortality estimates for country $i$ are as follows:

$$
\text { Excess }_{\mathrm{i}}=\text { Mortality rate }_{i, \text { pandemic period }}-\text { Mortality rate }_{i, 1965-1967}
$$

The pandemic period is from 1968 to 1970 for the Northern hemisphere and 1969 to 1970 for the Southern countries; Appendix Table 9 provides the climatic region list. Our analysis thus considers the seasonality of the virus trans-mission among the Northern and the Southern hemispheres. Specifically, the baseline measure uses an average excess mortality rate from 1968 to 1970 for 43 countries in the Northern hemisphere and the 1969-1970 period for 9 countries in the Southern hemisphere. After accounting for the two pandemic seasons' duration, the total excess mortality rate is around $0.023 \%$, consistent with the literature's estimated mortality rates (Table 1).

Many countries might not be significantly affected by the pandemic in 1968, and most countries had much higher mortality rates in the second wave 1969/1970. We use an alternative measure of the pandemic for robustness, defining the 1969-1970 period as the pandemic period ( "excess_b" variable in Table 2). On average "excess_b" is $11 \%$ higher than "excess_a," the baseline measure for the northern hemisphere. The correlation between the two measures of excess mortality is 0.95 . Also, we construct another alternative measure of excess mortality (excess_c) using the period 1963-1967 as the comparison period. On average "excess_c" is 13\% lower than the baseline measure "excess_a".

\section{Output Measures}

$$
\Delta Y_{i}=\mathrm{Y}_{\mathrm{i}, \text { pandemic period }}-\mathrm{Y}_{\mathrm{i}, 1965-1967}
$$

Equation (2) defines the deviation of the average real GDP growth rate during the two pandemic waves from that in the preceding period 1965-1967 (Output1 as the outcome variable $\Delta \mathrm{Y}_{i}$ ). The mean of this variable "Output1" is $1.30 \%$. For robustness, we use other measures of output. The variable "Output2" in Table 2 is from Eq. (2) applied to the pandemic period 1969-1970. The variable "Output3" uses the pre-pandemic period from 1963 to 1967. The correlation coefficients of these output measures are about 0.9 (Appendix Table 8).

\section{Productivity Measures}

We apply Eq. (2) to define "labor productivity" and "TFP" as the outcome variables, further shown in Table 2, measuring the deviations of the productivity growth rates during the pandemic from those in the preceding period (as the outcome variables). Labor productivity is the real output per worker. Total factor productivity TFP is the real output divided by the weighted productive capital input and the weighted labor input from the Penn World 
Tables $9.1^{7}$ We have 46 countries with data on labor productivity and 45 countries with $\mathrm{TFP}^{8}$. The average labor-productivity deviation is $1.61 \%$, and the TFP deviation is $2.74 \%$.

\section{Consumption and Investment}

Using Eq. (2) to define the consumption and investment as the outcome variables $\mathrm{Y}$, Table 2 shows, respectively, the deviations of real consumption and investment growth rates during the pandemic from those in the preceding period. The average deviation in consumption is $1.43 \%$, and the investment deviation is $0.91 \%$.

\section{Control Variables}

We use a set of control variables in our estimation following the literature, including inflation, government spending, trade openness, years of secondary schooling, population growth, and political right index all in the pre-pandemic period. Our selection of these controls follows Brainerd and Siegler (2003), Guimbeau et al. (2020), and Correia et al. (2020). Demographic, geographic, and initial economic factors control for differences in the pre-pandemic conditions. The demographic and geographic characteristics may also influence the mortality patterns of affected countries at the onset of an influenza outbreak; thus, we do not control these factors. Also, Correia et al. (2020) suggest that places with better institutions may have a lower cost of intervening and relatively better economic prospects during influenza outbreaks. Hence, we control for quality institutions using as a proxy the political right index.

Our controls are consistent with the literature; for example, a study by Guimbeau et al. (2020) on the consequential effect of the 1918 Influenza on agricultural productivity in Brazil. ${ }^{9}$ Data on output, productivity, and control variables are from Penn World Tables 9.1 and World Development Indicators; more details are in Appendix Tables 6, 7, 8 and 9.

\section{Empirical Specification}

To estimate the association between the H3N2 pandemic and output growth and TFP, we use a cross-section of 52 countries with available data to examine the pandemic as a common shock that affected all countries in the two pandemic waves 1968/69 and 1969/70. The dependent variables are the deviations of growth and productivity during the pandemic seasons from the preceding period (1965-1967). The estimating equation is as follows:

\footnotetext{
7 In the PWT 9.1, the 'productive capital input' measures firstly introduced are more appropriate for comparing productivity across countries and over time than the capital stock measures previously in the PWT 9.0. Specifically, measures of physical and human capital and estimates of productivity are based on the translog production function which allows for substitution elasticities to differ across countries and over time. In addition, the authors improve the measure of physical capital by estimating the user cost of capital and comparing the implicit rental price of capital and the level of capital services rather than capital stock.

8 The TFP level is in current PPPs with the United States as the base country, thus, we drop the US in the specification of TFP. Six countries in the sample do not have data on productivity include: Honduras, Mauritius, Nicaragua, Panama, Paraguay, and El Salvador.

9 See also Engelbrecht (1997); Dowrick and Nguyen (1989); Madsen (2007); Bonfiglioli (2008); Ayhan Kose et al. (2009); Ang and Madsen (2013); Oulton and Sebastiá-Barriel (2013); Dua and Garg (2019).
} 


$$
\Delta Y_{i}=\alpha \text { Excess }_{i}+\beta X_{\mathrm{i}, \mathrm{o}}+u_{i}
$$

where $\Delta \mathrm{Y}_{i}$ is the outcome variable of country i (output growth, TFP, consumption growth, investment growth). Excess $_{i}$ is the intensity of the pandemic, measured as the excess death rate from Influenza and pneumonia. $\mathrm{X}_{\mathrm{i}, \mathrm{o}}$ is the set of lagged control variables including inflation, government spending, trade openness, years of secondary schooling, population growth, and political right index (all in the period 1965-1967; annual averages). $\mathrm{u}_{\mathrm{i}}$ is the error terms. There are no significant correlations between the control variables and the pandemic measures (see Appendix Table 8).

\section{Estimation Results}

\section{Impact of the Pandemic on Output}

We rescale the excess mortality variables by its standard deviation to interpret its economic significance. ${ }^{10}$ The first two columns of Table 3 present the estimates of Eq. (3) without control variables using the baseline measure (Output1). Column 3.1 suggests that the pandemic (a standard deviation excess mortality rate of $0.0062 \%$ ) reduced real output growth by $1.2 \%$ per pandemic season. Using excess_b (a standard deviation of $0.0069 \%$ ) and excess_c (a standard deviation of $0.0059 \%$ ) provides consistent estimates. All pandemic measures explain about 19 percent of the variation in output during the pandemic outbreak if there no control variables.

The next two columns add control variables. Overall, the excess_a estimate in column 3.2 suggests an annual output loss of $1.2 \%$; similarly, for column 3.3 using excess_b and column 3.4 using excess_c. Thus, the two-year outbreak is associated with a cumulative output loss of $2.4 \%$. Using the Output2 (1969-70 deviation from pre-pandemic) gives higher estimates (columns 3.5 to 3.7 of Table 3) relative to the baseline estimates, suggesting that the adverse impact was larger in the second pandemic wave (1969/1970). The estimates for Output3 (1963-1967 as the pre-pandemic period) are also consistent with Output 1 and Output2, shown in columns 3.8 to 3.10 .

Table 4 provides estimates of real consumption and investment growth. The main results are supportive of the output estimates, though smaller. For consumption, the findings are consistent; the pandemic shock reduced consumption growth by $1.92 \%$ (column 4.3 ) and investment by $1.16 \%$ (column 4.8 ) over the two pandemic waves in the baseline.

Given the fact that we have few countries with data on productivity, we further examine the sensitivity of the estimates based on a sample of those 46 countries with productivity data. The results are provided in Appendix Tables 10 and 11, in which the estimates appear to be close to the baseline while the explanatory power generally increases.

\section{Impact of the Pandemic on Productivity}

The first two column of Table 5 report the pandemic's estimated impacts on labor productivity in the regressions without any additional controls. The pandemic reduced labor

\footnotetext{
10 In particular, the variable "excess_a" is weighted by its standard deviation which is 0.0062 (dividing the original excess mortality rate by this number). Thus, the coefficient is interpreted as the impact of a one standard-deviation pandemic shock (a rise in mortality rate by $0.0062 \%$ ) on the outcome variable. Likewise, the variable "excess_b) is weighted by its standard deviation which is 0.0069 .
} 


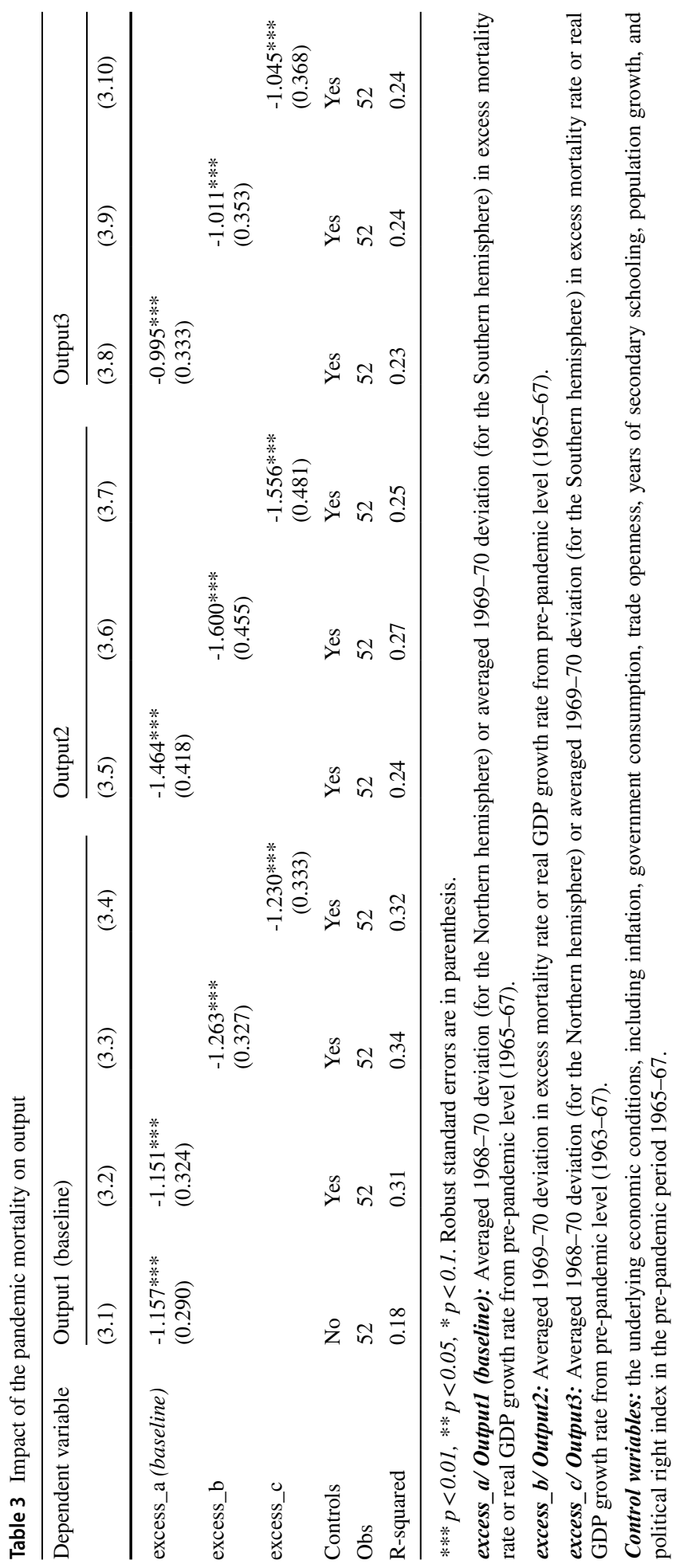




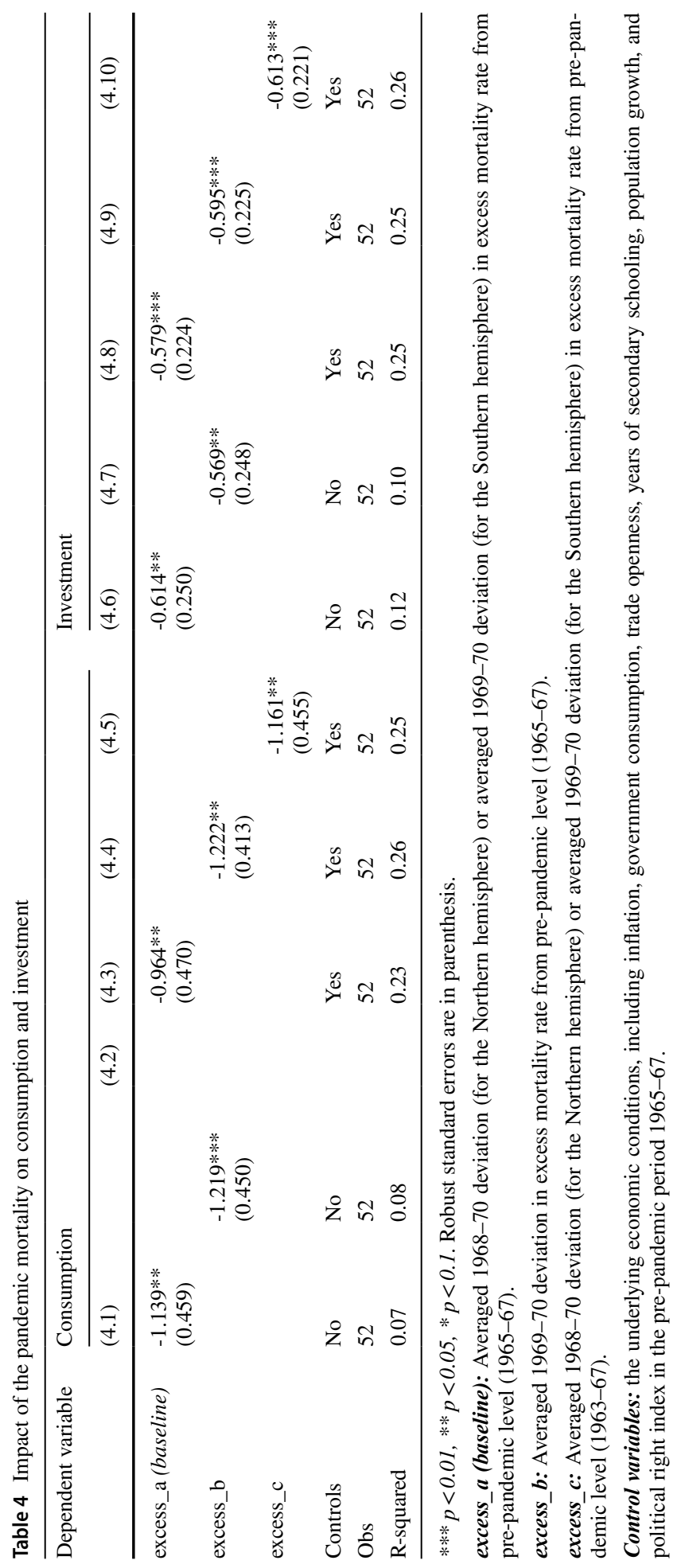




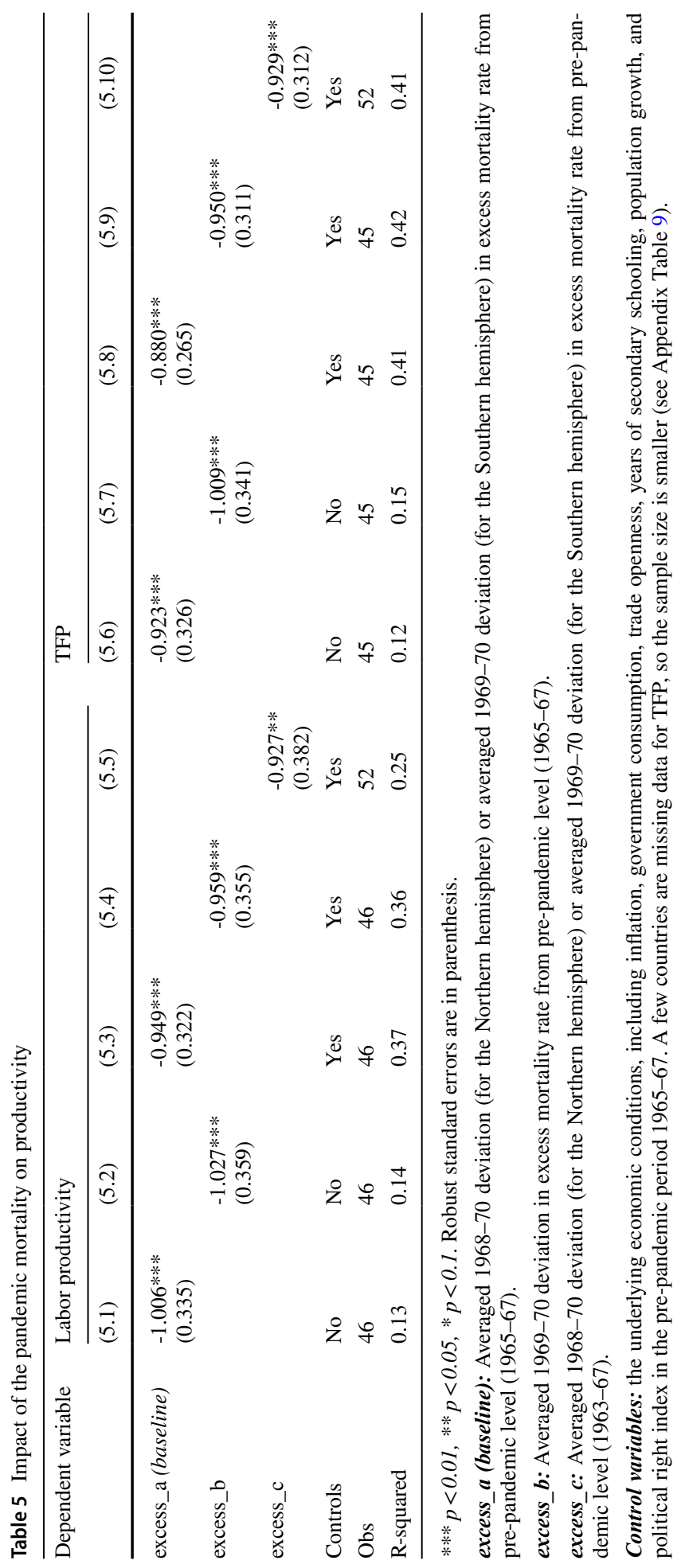


productivity by $1 \%$ per pandemic wave; the explanatory power $\left(\mathrm{R}^{2}\right)$ is $13 \%$. Adding all the regression controls, columns from 5.3 to 5.5 suggest that the loss in labor productivity is just below $1 \%$; the explanatory power $\left(\mathrm{R}^{2}\right)$ is up to $37 \%$. Over the two pandemic waves, the H3N2 Flu thus reduced the labor productivity by roughly $1.9 \%$. The estimates for TFP in Table 5 give a similar pattern.

Overall, we find that the pandemic's impact on consumption (-1.9\%), investment $(-1.2 \%)$, output $(-2.4 \%)$, and productivity $(-1.9 \%)$ is very substantial. The main findings support negative economic impacts on output and its components as well as the productivity, in the aftermath of the H3N2 Flu pandemic of 1968.

\section{Conclusion}

We find the excess mortality due to the 1968 H3N2 Influenza is associated with a decline in output, productivity, consumption, and investment in a sample of 52 countries. Due to data constraints, we are unable to account for non-pharmaceutical interventions (NPIs) in determining these outcomes. NPIs measures are designed to help reduce the mortality rate but the associated economic costs are uncertain. On the one hand, NPIs could have increased the economic costs of the pandemic, by imposing interruptions to the flows of goods and services. On the other hand, NPIs could have decreased these economic costs by preventing the spread of the virus, thereby enabling consumption, investment, and production activities, or even by establishing better practices that increase the confidence of individuals and firms in the economy (e.g., Noy et al. 2020). As a result, the lack of NPIs data may bias our findings downward if those preventive measures could have reduced the economic decline associated with Influenza.

\section{Appendix}

Table 6 Data sources

\begin{tabular}{lll}
\hline Variable & Description & Source \\
\hline mortality & $\begin{array}{l}\text { The number of deaths from Influenza and pneumonia } \\
\text { (WHO disease codes are 470-517 and 480-493) }\end{array}$ & WHO \\
gdp & real GDP at chained PPPs (in mil. 2011US\$) & PWT 9.1 \\
tfp & Total factor productivity, at current PPPs (USA=1) & \\
consumption & Real private consumption in mil. 2011US\$ (PPPs) & \\
investment & Real private investment in mil. 2011US\$ (PPPs) & \\
govt spending & Share of government consumption to GDP (\%) & \\
pop & Population (in millions) & \\
working population & Number of workers (in millions) & \\
cpi & Inflation (difference in the CPI in logs) & Wacziarg and Welch (2003) \\
open & Trade openness: a dummy variable & WDI \\
school & Years of secondary schooling & www.freedomhouse.org \\
pol & Political right index &
\end{tabular}




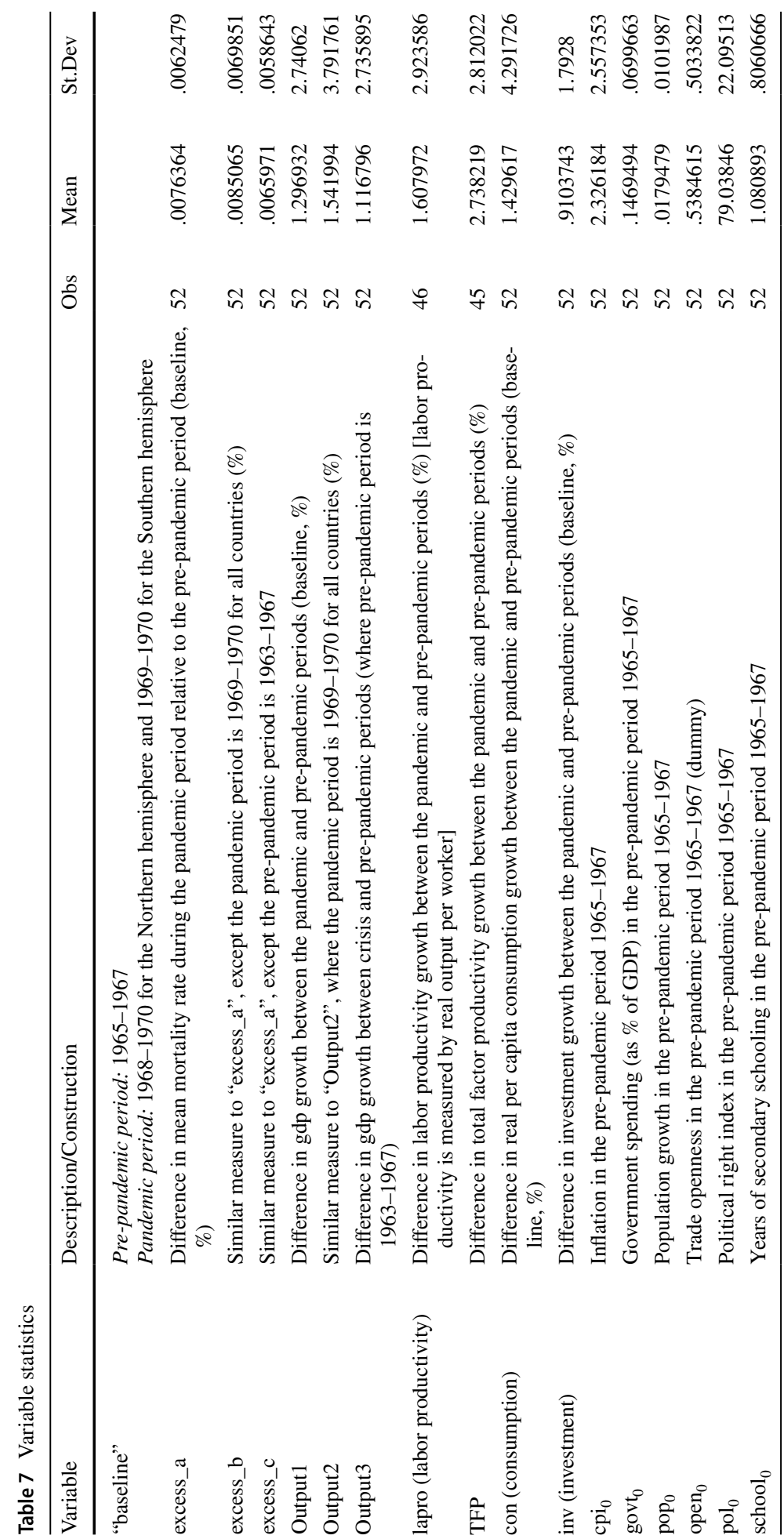




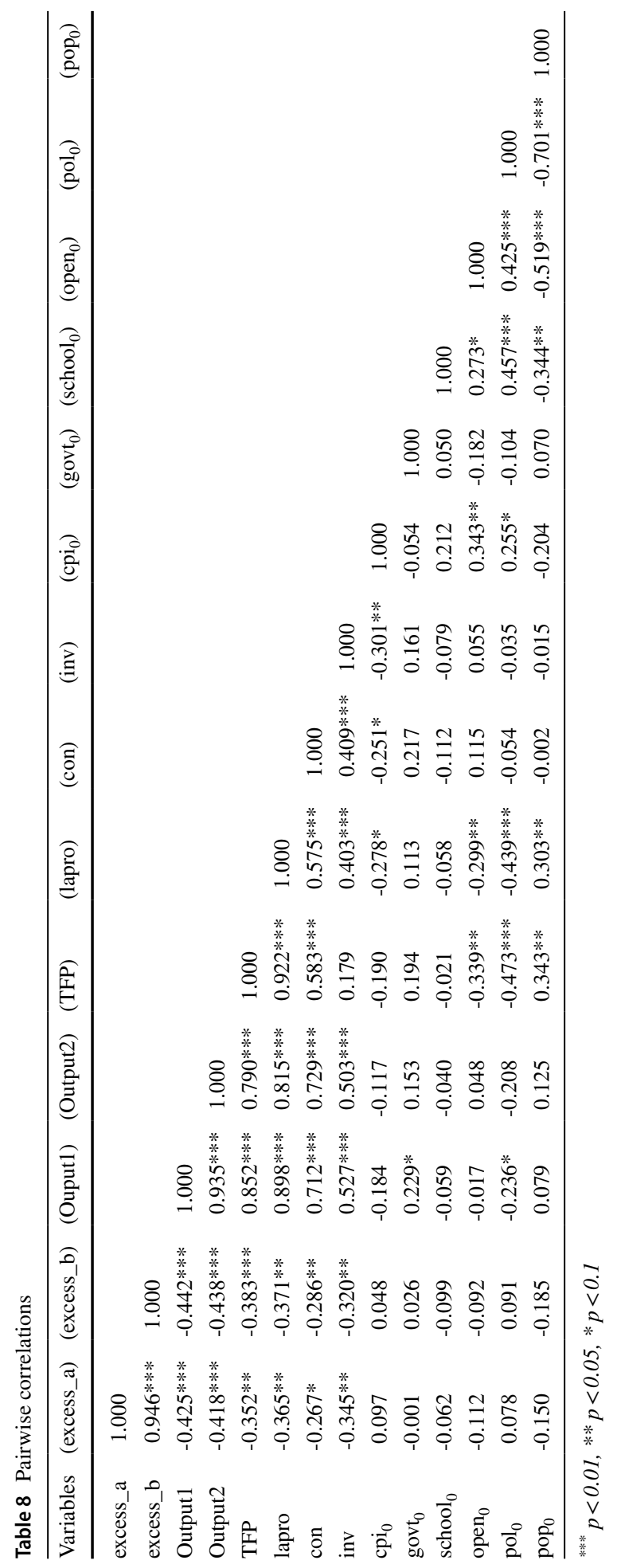




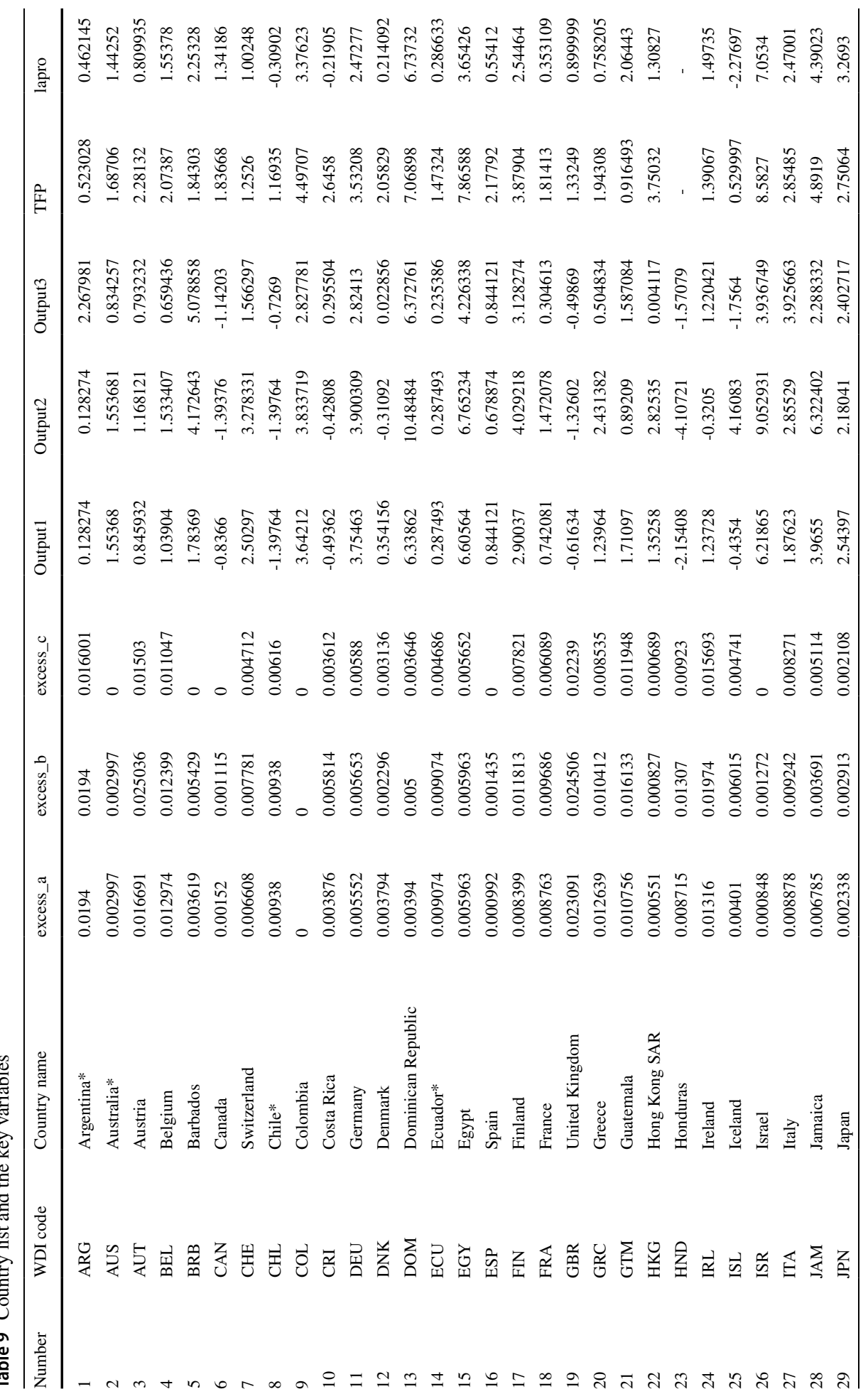




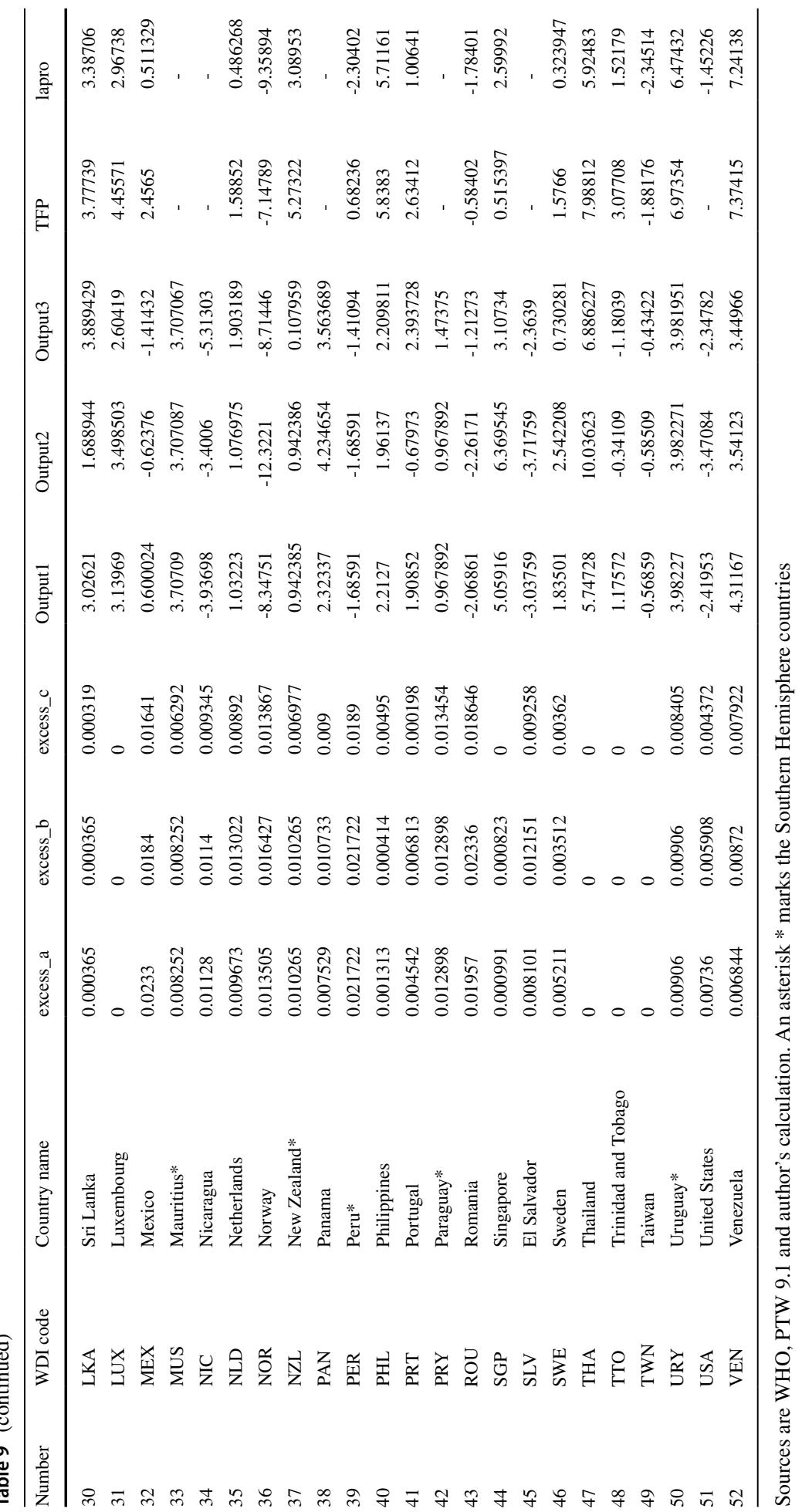




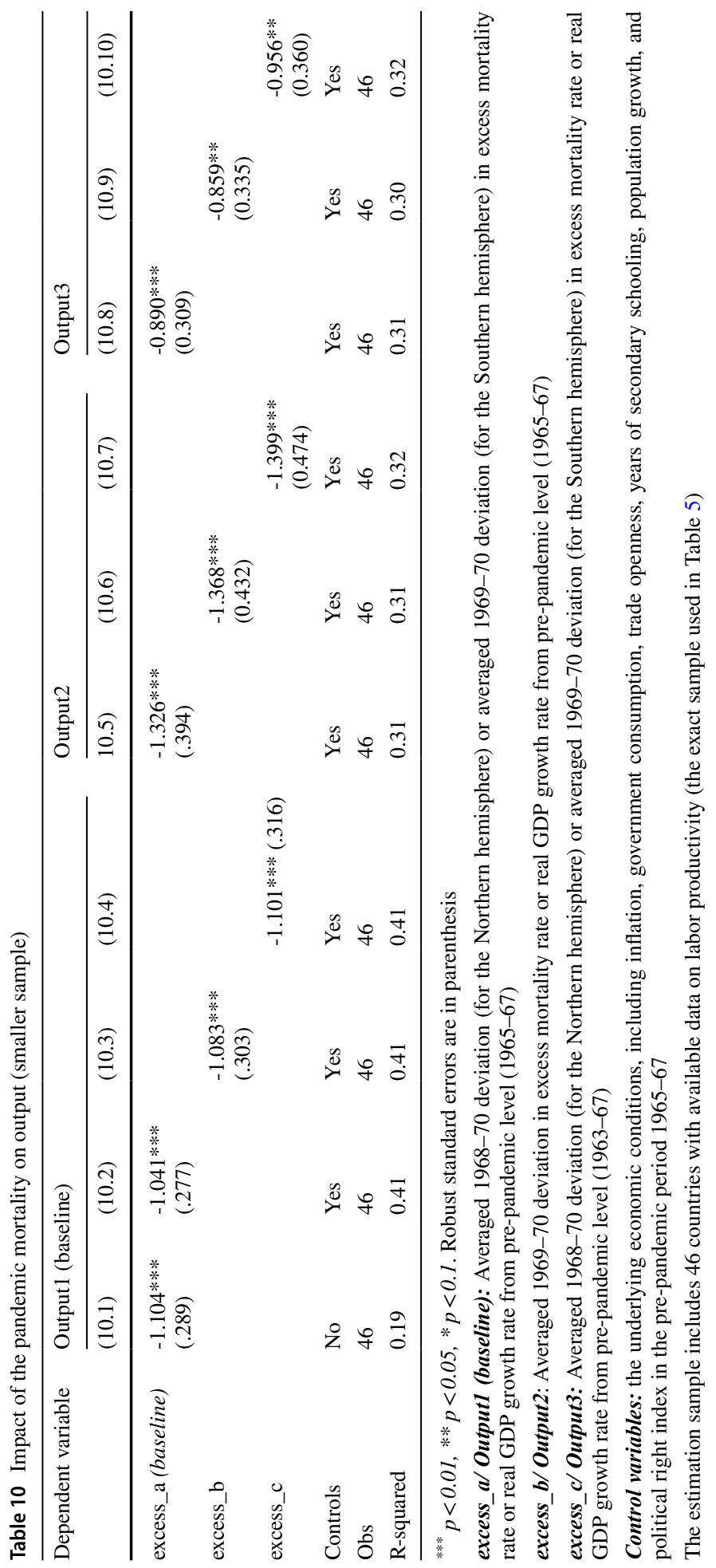




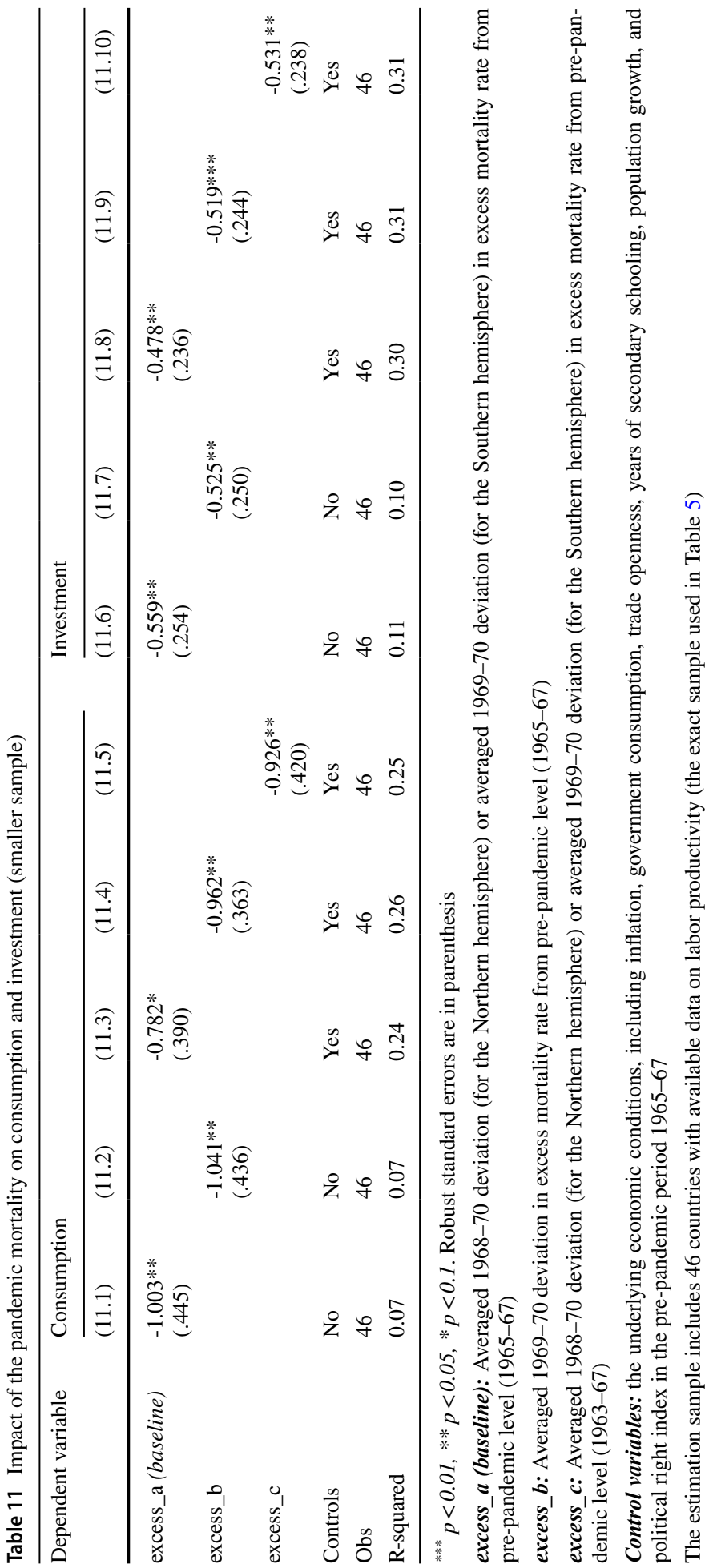


Data Availability The full dataset used in this study will be available from the corresponding upon request.

\section{Declarations}

Ethics Statement No ethical approval was required to conduct this study.

Conflict of Interest All authors have no conflicts of interest to declare.

\section{References}

Alistair Dieppe (2020) “Global Productivity,"\&nbsp;World Bank Publications, The World Bank, number 34015, August

Andersen, Asger \& Hansen, Emil Toft \& Johannesen, Niels \& Sheridan, Adam (2020) "Consumer Responses to the COVID-19 Crisis: Evidence from Bank Account Transaction Data,"\&nbsp;CEPR Discussion Papers\&nbsp; 14809

Ang JB, Madsen JB (2013) International R\&D spillovers and productivity trends in the Asian miracle countries. Econ Inq 51:1523-1541

AyhanKose M, Prasad ES, Terrones ME (2009) Does openness to international financial flows raise productivity growth? J Int Money Financ 28(4):554-580

Baker SR, Farrokhnia RA, Meyer S, Pagel M and Yannelis C (2020) How does household spending respond to an epidemic? Consumption during the 2020 COVID-19 Pandemic, NBER Working Papers\&nbsp;26949

Banco de Espana (2020) "Reference Macroeconomic Scenarios for the Spanish Economy after COVID19.” Economic Bulletin 2/2020, Banco de Espana, Madrid

Barro RJ, Ursúa JF and Weng J (2020) The Coronavirus and the Great Influenza Epidemic- lessons from the 'Spanish Flu' for the Coronavirus's potential effects on mortality and economic activity. CESifo Working Paper 8166

Beach B, Clay K and Saavedra M (2020). The 1918 Influenza Pandemic and its lessons for COVID-19. The Journal of Economic Literature, forthcoming

Biggerstaff M, Cauchemez S, Reed C, Gambhir M, Finelli L (2014) Estimates of the reproduction Number for seasonal, pandemic, and Zoonotic Influenza: a systematic review of the literature. BMC Infect Dis 14(1):480

Bodenhorn H (2020) Business in a Time of Spanish Influenza. NBER Working Paper No. 27495

Bonfiglioli A (2008) Financial integration, productivity and capital accumulation. J Int Econ 76(2):337-355

Brainerd E and Siegler M (2003) The Economic Effects of the 1918 Influenza Epidemic. CEPR Discussion Paper 3791, Centre for Economic Policy Research, London

Chang WK (1969) National influenza experience in Hong Kong, 1968. Bull World Health Organ 41(3-4-5):349-351

Chen H and Qian W and Wen Q (2020) The Impact of the COVID-19 pandemic on consumption: learning from high frequency transaction data (April 6, 2020). Available at:\&nbsp; https://ssrn.com/abstr act=3568574\&nbsp;or https://doi.org/10.2139/ssrn.3568574.

Coibion O, Gorodnichenko Y and Weber M (2020) The cost of the Covid-19 Crisis: Lockdowns, Macroeconomic Expectations, and Consumer Spending, NBER Working Paper \#27141

Correia S, Luck S, Verner E (2020) Pandemics depress the economy, Public Health Interventions Do Not: Evidence from the 1918 Flu. Available at SSRN: https://ssrn.com/abstract=3561560 or https://doi.org/ 10.2139/ssrn.3561560. Accessed 16 Jan 2021

Dahl CM, Hansen CW and Jensen PS (2020) The 1918 epidemic and a V-shape recession: evidence from municipal income data. Covid Economic \#6, 137-162

Dowrick S, Nguyen D-T (1989) OECD comparative economic growth 1950-85: catch-up and convergence. Am Econ Rev 79(5):1010-1030

Dua P, Garg NK (2019) Determinants of labour productivity: comparison between developing and developed countries of Asia-Pacific. Pac Econ Rev 24(5):686-704

Engelbrecht HJ (1997) International R\&D spillovers, human capital and productivity in the OECD economies: an empirical investigation. Eur Econ Rev 41:1479-1488

FED (1967) Growth and balance in the world economy. https://fraser.stlouisfed.org/files/docs/publications/ ERP/pages/3596_1965-1969.pdf. Accessed 28 Dec 2020 
Gharehgozli, Orkideh, et al (2020) Impact of COVID-19 on the Economic Output of the US Outbreak's Epicenter. Econ Disaster Clim Chang, 1-13

Guerrieri V, Lorenzoni G, Straub L and Werning I (2020) Macroeconomic implications of COVID-19: can negative supply shocks cause demand shortages? NBER Working Paper 26918

Guimbeau A, Menon N and Musacchio A (2020) The Brazilian Bombshell? The Long-Term Impact of the 1918 Influenza Pandemic the South American Way. NBER Working Paper No.26929

Jackson C, Vynnycky E, Mangtani P (2010) Estimates of the transmissibility of the 1968 (Hong Kong) influenza pandemic: evidence of increased transmissibility between successive waves. Am J Epidemiol 171(4):465-78

Jena PR et al (2021) Impact of COVID-19 on GDP of major economies: Application of the artificial neural network forecaster. Econ Anal Policy 69:324-339. https://www.sciencedirect.com/science/article/pii/ S0313592620304604? casa_token=_3Txh8XyeCEAAAAA:ZB0EhQdrrFm36VnOeRjHDGC0ZILrzPb_rsFW8r7hXLqGiIA4Ah3TKf2tQuGY0Tnar_wVm7-UUA. Accessed 18 Aug 2021

Joo H, Maskery BA, Berro AD, Rotz LD, Lee Y-K, Brown C (2019) Economic impact of the 2015 MERS outbreak on the Republic of Korea's Tourism-Related Industries. Health Secur 17(2):100-108

Katafuchi Y, Kurita K and Managi S (2020) COVID-19 with stigma: theory and evidence from mobility data, Econ Disaster Clim Chang. https://link.springer.com/article/10.1007/s41885-020-00077-w

Karlsson M, Nilsson T and Pichler S (2014) The impact of the 1918 Spanish flu epidemic on economic performance in Sweden, J Health Econ, Elsevier, vol. 36(C), 1-19

Keogh-Brown MR, Smith R (2008) The economic impacts of SARS: how does the reality match the predictions? Health Policy 88(1):110-120

Kholodilin KA and Rieth M (2020) Viral shocks to the world economy. DIW Discussion Paper 1861, Deutsches Institut für Wirtschaftsforschung, Berlin

Kurita K, Managi S (2020) COVID-19 and stigma: evolution of self-restraint behaviour, MPRA Paper No. 104042, University Library of Munich, Germany. https://mpra.ub.uni-muenchen.de/104042/. Accessed 18 Aug 2021

Lee J-W, McKibbin W (2004) Globalization and disease: the Case of SARS. Asian Econ Pap 3(1):112-131

Madsen JB (2007) Technology Spillover through Trade and TFP Convergence: 135 Years of Evidence for the OECD Countries. J Int Econ 72:464-480

Mandel A, Veetil VP (2020) The economic cost of covid lockdowns: an out-of-equilibrium analysis. Econ Disaster Clim Chang 2020:431-451

Martin A, Markhvida M, Hallegatte S (2020) Socio-economic Impacts of COVID-19 on household consumption and poverty. Econ Disaster Clim Chang 2020:1-27

Nakamura H, Managi S (2020) Airport risk of importation and exportation of the COVID-19 pandemic. Transport Policy 96:40-47. https://www.sciencedirect.com/science/article/pii/S0967070X20303516? via\%3Dihub. Accessed 18 Aug 2021

Noy I and Shields S (2019) The 2003 severe acute respiratory syndrome epidemic: a retroactive examination of economic costs. Asian Development Bank Economics Working Paper \#591

Noy I, Okubo T and Strobl E (2020) Are non-pharmaceutical interventions effective? The Japanese textile sector during the pandemic influenza of 1918-1920. CESifo Working paper

Oulton N and Sebastiá-Barriel M (2013) Long and short-term effects of the financial crisis on labour productivity, capital and output, Bank of England Working Paper No. 470

Rassy D, Smith RD (2013) The economic impact of H1N1 on Mexico's tourist and pork sectors. Health Econ 22(7):824-834

Siu A, Wong YCR (2004) Economic impact of SARS: the case of Hong Kong. Asian Econ Pap 3(1):62-83

United Nations (1969) World economic and social survey archive: 1960-1969. https://www.un.org/devel opment/desa/dpad/publication/world-economic-and-social-survey-archive-1960-1969/. Accessed 28 Dec 2020

Viboud C, Grais RF, Lafont BA, Miller MA, Simonsen L (2005) Multinational impact of the 1968 Hong Kong influenza pandemic: evidence for a smoldering pandemic. J Infect Dis 192(2):233-248

World Bank (2020) Global economic prospects, June 2020. World Bank, Washington, DC. https://openk nowledge.worldbank.org/handle/10986/33748. Accessed 28 Dec 2020

Publisher's Note Springer Nature remains neutral with regard to jurisdictional claims in published maps and institutional affiliations. 